\title{
Angiotensin converting enzyme inhibitors and magnesium conservation in patients with congestive cardiac failure
}

\author{
R N Stevenson, Charlotte Keywood, A A Amadi, J R Davies, D L H Patterson
}

\begin{abstract}
Objective-To investigate whether angiotensin converting enzyme inhibitors reduce diuretic induced magnesium excretion in patients in congestive cardiac failure.

Design-Cohort analytic study.

Setting-A London district general hospital.
\end{abstract}

Subjects-Thirty four patients with chronic congestive cardiac failure caused by ischaemic heart disease or cardiomyopathy selected consecutively from inpatients under the care of two consultant cardiologists. Nineteen patients (group 1) on diuretics alone were compared with 15 patients (group 2) taking diuretics plus either enalapril or captopril. All drug regimens were stable for at least three months before the study. Patients with impaired renal function (plasma creatinine $>120$ $\mu \mathrm{mol} / 1)$ were excluded.

Interventions-An intravenous loading dose of magnesium sulphate was given to minimise the variability in baseline magnesium state.

Main outcome measure-Total urine magnesium excretion and creatinine clearance in 24 hour urine collections.

Results-Plasma magnesium was similar in the two groups. However, 24 hour urine magnesium excretion was significantly lower in group 2 than in group 1. Furthermore, creatinine clearance was also significantly lower in group 2 and correlated strongly with magnesium excretion. There was no such relation in group 1 . There was no difference in fractional clearance of magnesium between groups.

Conclusion-Angiotensin converting enzyme inhibitors have an important magnesium conserving action, possibly via their effect on glomerular filtration rate.

Cardiac Department, Whittington Hospital, London

R N Stevenson

C Keywood

A A Amadi

J R Davies

D L H Patterson

Correspondence to

Dr R N Stevenson, Cardiac Department, London Chest Hospital, Bonner Road, London E2 9JX.

Accepted for publication 26 March 1991

There is growing awareness of the importance of magensium metabolism in cardiovascular medicine and in particular the association between hypomagnesaemia and cardiac arrhythmias. ${ }^{1}$ Recent evidence suggests that hypomagnesaemia in patients with congestive cardiac failure is related to a poor prognosis owing to a high prevalence of ventricular arrhythmias and to an increased risk of sudden death. ${ }^{2}$ Interestingly, hypermagnesaemia in these patients may also be associated with an adverse prognosis, though raised plasma concentrations of magnesium may simply be a marker of important renal impairment caused by severe cardiac dysfunction.

Angiotensin converting enzyme inhibitors are commonly used with loop diuretics to treat congestive cardiac failure. It is well recognised that loop diuretics can cause hypomagnesaemia, ${ }^{3}$ and furthermore, that plasma magnesium concentrations can be normal in the presence of significant tissue depletion. ${ }^{4}$ Angiotensin converting enzyme inhibitors may attenuate the hypomagnesaemic action of loop diuretics; their effect on urinary magnesium excretion has not been adequately studied. We investigated the effects of angiotensin converting enzyme inhibitors on diuretic induced magnesium excretion in patients with congestive cardiac failure.

\section{Patients and methods}

We studied 34 patients with chronic congestive cardiac failure caused by ischaemic heart disease or cardiomyopathy. Group $1(n=19)$ patients were treated with a loop diuretic (either frusemide with or without amiloride or bumetanide) alone. Patients in group 2 $(\mathrm{n}=15)$ were taking both a loop diuretic plus an angiotensin converting enzyme inhibitor (enalapril or captopril). All drug regimens were kept stable for at least three months before the study. Patients with impaired renal function (plasma creatinine $>120 \mu \mathrm{mol} / \mathrm{l}$ ) were excluded. Other exclusion criteria included factors likely to disturb renal magnesium homoeostasis such as alcoholism, malabsorption, and ingestion of compounds containing magnesium. Blood was taken for baseline plasma magnesium and creatinine estimations. To minimise the variability in the

Table 1 Age, weight (kg), and dose of diuretic (equivalent to dose of frusemide in $\mathrm{mg}$ ) in the two patient groups (mean (SEM))

\begin{tabular}{lll}
\hline & $\begin{array}{l}\text { Group 1 } \\
\text { (Diuretics } \\
\text { only) }\end{array}$ & $\begin{array}{l}\text { Group 2 } \\
\text { (Diuretics + ACE } \\
\text { inhibitors) }\end{array}$ \\
\hline Age & $69(2 \cdot 5)$ & $69(2 \cdot 6)$ \\
Weight (kg) & $70(2 \cdot 7)$ & $71(3 \cdot 8)$ \\
$\begin{array}{l}\text { Diuretic dose } \\
\text { Dose ACE inhibitor } \\
\text { (=mg enalapril) }\end{array}$ & $80(8 \cdot 4)$ & $91(9 \cdot 9)$ \\
\hline
\end{tabular}


Table 2 Plasma magnesium ( $m m o l / l)$ and $24 \mathrm{~h}$ urinary magnesium ( $m m o l)$ in the two groups (mean (SEM)

\begin{tabular}{llll}
\hline & $\begin{array}{l}\text { Group } 1 \\
\text { (Diuretics only) }\end{array}$ & $\begin{array}{l}\text { Group 2 } \\
\text { (Diuretics and ACE inhibitors) }\end{array}$ & $p$ Value \\
\hline Plasma magnesium $(\mathrm{mmol} / \mathrm{l})$ & $0 \cdot 87(0.02)$ & $0 \cdot 86(0.02)$ & $\mathrm{NS}$ \\
$24 \mathrm{~h}$ urine magnesium $(\mathrm{mmol} / 24 \mathrm{~h})$ & $26 \cdot 0(1 \cdot 0)$ & $18 \cdot 5(1 \cdot 4)$ & 0.001 \\
\hline
\end{tabular}

baseline state of total body magnesium all patients were given an intravenous loading dose of magnesium sulphate $(30 \mathrm{mmol}$ in $500 \mathrm{ml}$ of $5 \%$ dextrose given over eight hours). This loading regimen has been used in previous studies of magnesium turnover. ${ }^{6} \mathrm{We}$ measured total urinary magnesium and creatinine in urine collected for 24 hours.

The statistical significance of differences between the two groups was assessed by the two tailed $t$ test for groups of non-paired observations. Linear regression analysis was applied to test for a relation between sets of variables within a group.

\section{Results}

Patients in the two groups were well matched for age, weight, and dose of diuretic (table 1). Table 2 shows the mean (SEM) values of plasma magnesium and 24 hour urinary magnesium in the two groups of patients. Plasma magnesium concentrations were similar in both groups and were within the normal range. However, the 24 hour excretion of magnesium was significantly lower in the patients (group 2) treated with angiotensin converting enzyme inhibitor. Table 3 shows the mean (SEM) values of plasma creatinine, creatinine clearance, and fractional clearance of magnesium. Although plasma creatine concentrations were comparable, creatinine clearance was significantly lower in group 2 . There was no significant difference in the fractional clearance of magnesium between the groups.

Linear regression analysis showed a strong relation ( $\mathrm{p}=0.001)$ between urine magnesium excretion and creatinine clearance in patients treated with angiotensin converting enzyme inhibitors (figure). There was no such relation in the patients who were not treated with angiotensin converting enzyme inhibitors (group 1).

\section{Discussion}

Our results suggest that angiotensin converting enzyme inhibitors have a magnesium conserving effect when they are given in conjunction with loop diuretics to treat congestive cardiac failure. As far as we are aware this effect has not been shown before. Previous studies of angiotensin converting enzyme inhibitors and magnesium turnover have been restricted to

Table 3 Plasma creatinine ( $\mu$ mol $/ l)$, creatinine clearance $(\mathrm{ml} / \mathrm{min})$, and fractional clearance of magnesium (\%) in the two groups (mean (SEM)

\begin{tabular}{|c|c|c|c|}
\hline & $\begin{array}{l}\text { Group } 1 \\
\text { (Diuretics } \\
\text { only) }\end{array}$ & $\begin{array}{l}\text { Group } 2 \\
\text { (Diuretics and } A C E \\
\text { inhibitors) }\end{array}$ & p Value \\
\hline $\begin{array}{l}\text { Plasma creatinine }(\mu \mathrm{mol} / \mathrm{l}) \\
\text { Creatinine clearance }(\mathrm{ml} / \mathrm{min}) \\
\text { Fractional magnesium clearance }(\%)\end{array}$ & $\begin{array}{l}98(5 \cdot 5) \\
74(5 \cdot 9) \\
29 \cdot 5(2 \cdot 1)\end{array}$ & $\begin{array}{l}112(5 \cdot 3) \\
49(5 \cdot 0) \\
32 \cdot 6(2 \cdot 4)\end{array}$ & $\begin{array}{l}\text { NS } \\
0 \cdot 002 \\
\text { NS }\end{array}$ \\
\hline
\end{tabular}

plasma concentrations, and the results have been conflicting..$^{58}$ In this study, plasma magnesium concentrations were within the normal range with no significant difference between the two groups. It might be expected that the group treated with diuretics alone would have a lower plasma magnesium concentration than the group receiving diuretics and angiotensin converting enzyme inhibitors. However, other workers showed that plasma magnesium concentrations do not correlate with tissue concentrations, ${ }^{49}$ and thus plasma concentrations within the normal range do not exclude significant tissue or total body depletion. To establish whether tissue magnesium concentrations differed between the two groups, and in particular whether patients in group 1 were tissue depleted, would have required analysis of muscle biopsy specimens.

About $80 \%$ of plasma magnesium is filtered at the glomerulus and most is reabsorbed in the ascending loop of Henle. ${ }^{10}$ Loop diuretics increase urinary magnesium losses largely by blocking reabsorption at this site, though secondary hyperaldosteronism may be a contributory factor. ${ }^{1011}$

In this study patients in group 2 had a significantly lower glomerular filtration rate, which we propose was directly related to angiotensin converting enzyme inhibition. Furthermore, the strong correlation between urinary magnesium excretion and creatinine clearance in group 2 suggests that magnesium conservation may largely be a result of the reduction in glomerular filtration rate. The absence of such a correlation in group 1 may mean that magnesium excretion only becomes dependent on glomerular filtration rate when this is reduced below a critical value. Fractional clearance of magnesium was similar between the two groups, suggesting that angiotensin enzyme inhibitors do not have a significant effect on magnesium reabsorption at a site other than the glomerulus. Nevertheless, it is also possible that the anti-aldosterone action of angiotensin converting enzyme inhibitors may

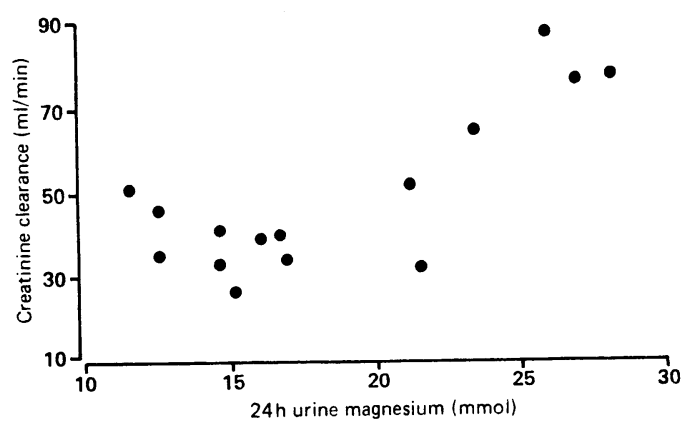

Relation between creatinine clearance and 24 h urine magnesium in patients on diuretics and angiotensin converting enzyme inhibitors. 
contribute to magnesium conservation, though for confirmation this needs further investigation. An alternative explanation for our findings is that by chance the angiotensin converting enzyme inhibitor group had worse renal function and the differences shown were attributable to this and not to the drugs themselves. However, we think that this is an unlikely explanation.

First, we were careful to exclude from this study patients likely to have intrinsic renal disease. Secondly enalapril (and presumably other angotensin converting enzyme inhibitors) has been shown to reduce the glomerular filtration rate measured both by isotope techniques and by creatinine clearance. ${ }^{5}$ There is increasing evidence that in severe cardiac failure the glomerular filtration rate is maintained by angiotensin mediated vasoconstriction of the efferent glomerular arteriole. By inhibiting this mechanism, angotensin converting enzyme inhibitors reduce the glomerular hydrostatic pressure and hence the glomerular filtration rate. ${ }^{12}$

The only important difference between the two groups in terms of concurrent medication was that more patients in group 1 were receiving amiloride (15 in group 1 and four in group 2). This is unlikely to have adversely influenced our results because amiloride can have only a weak magnesium conserving action, ${ }^{13}$ and so would tend to lessen the difference seen between the groups. The only other commonly prescribed drugs were long acting nitrates and digoxin, both of which were evenly distributed between groups.

The high incidence of sudden death among patients in cardiac failure implies that lethal ventricular arrhythmias are in part responsible. Hypomagnesaemia has been associated with ventricular extrasystoles and this may partly explain the high incidence of ventricular arrhythmias in patients in congestive cardiac failure. ${ }^{14}$
We suggest that angiotensin converting enzyme inhibitors have an important magnesium sparing action in patients whom are liable to depletion by loop diuretics.

We thank Dr S MacFarlan for measuring the magnesium concentratons and Merck, Sharpe, and Dome for financial support.

1 Whang R. Magnesium deficiency: pathogenesis, prevalence and clinical implications. Am.J Med 1987;82(suppl 3A):24-9.

2 Gottlieb SS, Baruch L, Kukin ML, et al. Prognostic importance of the serum magnesium concentration in patients with congestive heart failure. J Am Coll Cardiol 1990;16:827-31

3 Ryan MP. Diuretics and potassium/magnesium depletion Am J Med 1987;82:(suppl 3A):38-42.

4 Dorup I, Skajaa K, Clausen T, Kjeldsen K. Reduced concentrations of potassium, magnesium, and sodiumpotassium pumps in human skeletal muscle during treatment with diuretics. $B M J 1988 ; 296: 455-8$.

5 Cleland JGF, Dargie HJ, Ball SG, et al. Effects of enalapril in heart failure: a double blind study of effects on exercise performance, renal function, hormones, and metabolic performance, renal function, horm

6 Dyckner T, Wester PO. Magnesium deficiency: guidelines for diagnosis and substitution therapy. Acta Med Scand for diagnosis and substit

7 Zumkley VH, Bertram HP, Vetter H, et al. Magnesium and zinc concentrations in plasma and erythrocytes under zinc concentrations in plasma and erythrocytes under angiotensin con $1983 ; 2: 74-7$

8 Vandenburg MJ, Robinson P, Arr S, Cooper W, Currie WJC. Serum magnesium is unaffected by angiotensin converting enzyme inhibition. Clin Sci 1985;68(suppl 11):77p-8p.

9 Dyckner T, Wester PO. Potassium/magnesium depletion in patients with cardiovascular disease. Am J Med 1987; 82:(suppl 3A): 11-6.

10 Dirks JH. The kidney and magnesium regulation. Kidney Int 1983;23:771-7.

11 Rasmussen H, McNair P, Goransson L, et al. Magnesium deficiency in patients with ischaemic heart disease with and without acute myocardial infarction uncovered by an intravenous loading dose. Arch Intern Med 1988;148. 329-32.

12 Packer M, Lee WH, Kessler PD. Preservation of glomerular filtration rate in human heart failure by activation of the renin-angiotensin system. Circulation 1986;74:766-4.

13 Leary WP, Reyes AJ, van de Byl K. Effect of a combination of hydrochlorothiazide and amiloride on urinary magnesium excretion in healthy adults. Curr Ther Res 1984;35: excretion

14 Hollifield JW. Magnesium depletion, diuretics, and arrythmias. Am J Med 1987;82(suppl 3A):30-7. 